\section{Oral and Poster Abstract Sessions}

\section{UNDER-REPORTING OF OCCUPATIONAL NOISE-INDUCED HEARING LOSS, CURRENT SITUATION, AND POSSIBLE SOLUTIONS IN THAILAND AND OTHER DEVELOPING COUNTRIES}

1,2T Chernbamrung, 'S Chanduaywit, ${ }^{1} \mathrm{~W}$ Hwanraruen, ${ }^{1} \mathrm{~W}$ Inchit. 'Occupational Medicine Department, Rayong Hospital, Rayong, Thailand; 'Faculty of Medicine Chulalongkorn University, Bangkok, Thailand

\subsection{6/oemed-2018-ICOHabstracts.881}

Introduction In 2015, Thai Workmen's Compensation Fund (TWCF) reported only 3 cases of Occupational Noise-induced Hearing Loss (ONIHL) among nearly 10 millions workers. Thai labour laws stated that hearing conservative programs (HCPs) was mandatory for noisy work stations. Baseline audiometric analysis must be performed using NIOSH criteria (SigTS). However, retest and referral to occupational physicians (OPs) for work-related assessment were usually not performed for Thai workers with 1 st $15 \mathrm{~dB}$ shift. Baseline audiometric analysis was not properly performed in many industries. For example, not all the previous test were considered in baseline revision or baseline may never be revised. All these leaded to under-reporting of ONIHL in Thailand.

Methods For remedy the situation, pilot study was conducted on 2539 workers among 17 chemical industries in eastern region of Thailand. 10 years audiometric results (2007-2016) were collected and analysed using SigTS and OSHA criteria (STS). Baseline revisions for each criteria were performed by OPs. The results were compared with those without baseline revision.

Result Without baseline revision, the accumulation, increasing of abnormalities over years could be the cause of unnecessary investigations. With proper baseline revisions, the incidence of SigTS, STS, and age corrected STS were only $19.27 \%$, $10.21 \%$, and $4.05 \%$ respectively. After age correction, only $2.61 \%$ had to visit OPs for work-related assessment each year. Discussion STS with age correction and proper baseline revisions dramatically reduced total cost of investigations. This should be acceptable for industries in Thailand and other developping countries. Recommendation for Thai Ministry of Labour to revise HCPs regulations were:

- Baseline revision performed properly by OPs should be mandatory,

- Age corrected STS was the most cost-effective and practicable,

- All workers with worsening hearing must be referred to OPs and then TWCF, and

- Annually, HCPs installed industries must quantitatively evaluated ONIHL (diagnosed by OPs), SigTS, STS, and age corrected STS.

\section{VALIDATION OF THAI-NORDIC SAFETY CLIMATE QUESTIONNAIRE AND SAFETY CLIMATE IN THAI EMPLOYEES}

Thitiworn Choosong. Prince of Songkla University, Hatyai, Songkhla, Thailand

10.1136/oemed-2018-ICOHabstracts.882

Introduction To prevent workers' injury and illness during their working life, the occupational health and safety management system is worldwide implemented in manufacturing. The safety climate can be identified the currently situation of occupational health and safety management system in organisation. The Nordic safety climate questionnaire (NOSACQ-50) is a tool that can be measure the safety climate in both low and high risk level manufacturing. Therefore, this questionnaire will be used in this study.

Objective To validate the NOSACQ-Thai questionnaire using exploratory analysis and to assess the situation of safety climate condition in Thailand

Material and method After forward and backward translation of the NOSACQ-Thai questionnaire were performed, 3 expertise in occupational health and safety were examined the content validity and revised questionnaire to easy language for worker. There were 1141 of workers and hospital personnel, from 6 manufacturing and one university hospital, voluntary participated to test the questionnaire in this study.

Results The NOSACQ-Thai questionnaire included 5 dimensions with 42 items and $45 \%$ of variance. The Cronbach's alpha values of the safety climate dimension of 'management's engagement and empowerment', 'management safety priority and justice', 'employees' engagement to safety', ' employees' risk acceptance', and ' safety activity and efficacy' were 0.86 , $0.76,0.89,0.70$, and 0.74 , respectively. The highest safety climate score was the dimension of 'employees' engagement to safety' $(3.30 \pm 0.40)$ while the lowest score was the dimension of 'employees' risk acceptance' $(2.80 \pm 0.50)$. The safety climate score were significantly difference between leaders' and workers' group and also among all enterprises.

Conclusion The NOSACQ-Thai show a well validated and predictable the safety climate in all enterprises.

\section{INTEGRATED APPROACH TO AN OCCUPATIONAL HEALTH IN SOUTH AFRICA}

Kim Davies* . Department of Defense Pretoria, South Africa

\subsection{6/oemed-2018-ICOHabstracts.883}

Introduction South Africa is a developing, resource constrained country with a quadruple burden of disease. The health delivery model is based in primary health care of which the nurses are the cornerstone. Occupational Health Nursing (OHN) has had to evolve in this ever changing health service environment. This has created a need for an integrated approach to the Occupational Health program within the work place. The work environment in the 21 st Century will pose significant challenges to Occupational Health.

Methods Careful consideration is therefore required with respect to the selection, monitoring and evaluation of specialised occupational health services. Critical to the selection of integrated $\mathrm{OH}$ services is the scope of practice and competencies of the OHN need clearly defined.

Results The success of OHN providing an $\mathrm{OH}$ service is a matrix model of applied activities which is totally integrated into an Occupational health program. Within the multi professional team the $\mathrm{OHN}$ is best equipped to identify the needs and advise on the optimum utilisation for all. This will enable a more productive workforce.

Discussion The challenge for $\mathrm{OHN}$ is the evolving dynamic work environment in which the OHN finds herself, one which has increasing use of technology, emerging global threats to health and evolving risks to health of workers. The 
OHN has to be flexible and adaptive in order to meet the demands of this dynamic worker health environment. One solution to this complex health milieu is an integrated model of $\mathrm{OH}$ services in order to meet the difficulty of the health and wellness demands of workers in a complicated environment of risk.

\section{COMPARING TWO APPROACHES TO SCORING ALLOSTATIC LOAD IN BRAZILIAN CIVIL SERVANTS}

${ }^{1,2}{ }^{2}$ N Eto*, ${ }^{1}$ RS Santos, ${ }^{1}$ ECP Melo, ${ }^{3}$ RH Griep, ${ }^{2} \mathrm{~S}$ Toivanen. ${ }^{1}$ National School of Public Health, Oswaldo Cruz Foundation, Rio de Janeiro, Brazil; ${ }^{2}$ Centre for Health Equity Studies, Stockholms Universitet, Karolinska Institutet, Stockholm, Sweden; ${ }^{3}$ Laboratory of Health and Environment Education, Oswaldo Cruz Foundation, Rio de Janeiro, Brazil

\subsection{6/oemed-2018-ICOHabstracts.884}

Introduction Several international studies have used the allostatic load as an important multi-dimensional index to indicate chronic stress. Measurement of allostatic load has been done through parameters from various biological systems. Through its measurement, it's possible to assess the consequences of chronic stress on several systems, and also predict, prevent or delay chronic diseases that may occur later. Despite its importance, methodological issues regarding its operationalization remains. The aim of our study was to compare two approaches to scoring allostatic load.

Methods Data were obtained from the baseline of the Brazilian Longitudinal Study of Adult Health (ELSA-Brasil). The sample included 10965 active civil servants aged 34-74 years old. The allostatic load was measured based on 15 biologic parameters, including neurophysiological, metabolic, cardiovascular and inflammatory measurements. We compared two approaches to scoring allostatic load - based on clinical and risk quartile thresholds. Socioeconomic variables such as age, gender, skin colour and educational level were analysed. We performed descriptive analyses as mean, standard deviation and prevalence and conduced Student's $t$ test, ANOVA and linear regression analysis. Data were analysed using $\mathrm{R}$.

Results The findings showed that the percentage of individuals with high risk biologic parameters were different according to allostatic load scoring approaches. The mean values of the allostatic load clinically based were higher in all socioeconomic variables compared to the allostatic load quartile based. Nevertheless, in the linear regression model the magnitude of association observed was similar when comparing the both allostatic load scoring approaches.

Discussion This is the first Brazilian study that explores different approaches to scoring allostatic load. Besides, our study highlight the importance of studying the allostatic load at Brazilian context and how it can be used as a potential tool to occupational health and practice and contribute to prevent chronic diseases related to the chronic exposure to stress.

\section{PREVALENCE OF GASTROINTESTINAL DISEASES IN BRAZILIAN WORKERS RECEIVING SICK LEAVE BENEFITS - A RETROSPECTIVE STUDY}

IS Marineli, NC Rodrigues, VR Silva, LAF Cardillo, LR Ferreira. Centro Universitário das Faculdades Associadas de Ensino - FAE, São João da Boa Vista, Brazil

10.1136/oemed-2018-ICOHabstracts.885
Introduction Gastrointestinal diseases in Brazil can be responsible for work disability, making employees eligible to receive sick leave benefits. The aim of this study was to determine the gastrointestinal tract diseases causing the most frequent number of sick leave benefits from the National Institute of Social Security (INSS) and the profile of these workers to understand better the occurrence of these pathologies amongst workers.

Methods A retrospective study was conducted between January 2014 and February 2017. We selected 3260 patients diagnosed with gastrointestinal diseases, who had received temporary social security benefits from INSS. The samples were submitted to data collection including: sex, age, occupation, and international classification of diseases (ICD). Diseases with higher prevalence were analysed.

Results The study revealed that the most prevalent gastrointestinal disease included abdominal hernias (ICD K40-K42-K43) in 1328 workers, cholelithiasis (ICD K80) in 1298 patients, acute appendicitis (ICD K35) 634 cases. The results showed that $54 \%$ were males, with a mean age of 43 years. However, cholelithiasis affected mostly females. Amongst the hernias, the most prevalent was inguinal hernia followed by umbilical and ventral hernias. All of the workers received temporary sickleave benefit, but only $0.05 \%$ had the benefit of disability retirement and $0.35 \%$ sick-leave benefit due to work-related accidents (associated with hernia).

Discussion The data obtained allowed us to evaluate that the most frequent gastrointestinal diseases associated with sickleave benefits were those related to surgical management. The appearance of abdominal wall hernias may occur due to increased intra-abdominal pressure, associated with intense physical exertion made by some workers. Dietary habits are a risk factor for appendicitis, especially a diet with low fibre intake. Fatty foods, on the other hand, may influence the occurrence of cholelithiasis. These data may help understand the main factors associated with work disability due to gastrointestinal diseases.

\section{SICK LEAVE BENEFITS BY DIABETES MELLITUS: A RETROSPECTIVE EPIDEMIOLOGICAL STUDY}

DVS Vitor*, VR Batalini, RV Brito, CA Baptista, PI Scardovelli, LR Ferreira. UNIFAE School of Medicine, São João da Boa Vista, São Paulo State, Brazil

\subsection{6/oemed-2018-ICOHabstracts.886}

Introduction Diabetes mellitus is a disease that has a high prevalence around the world. In 2014, the World Health Organisation estimated that 422 million adults had the disease, worldwide. It is classified as being a chronic non-transmissible disease, and it is one of the main causes of disability, which can negatively affect productivity in active workers. In Brazil, the National Institute of Social Security (INSS) is responsible for granting benefits and salaries in cases of absenteeism due to illness.

Methods A retrospective study based on analysis of 184 patients who requested sick leave benefits due to diabetes mellitus from the Brazilian National of Social Security Institute (INSS), characterising the age, gender and employment situation through the ICD-10 (E10, E11 and E14) from January 2014 to February 2016.

Results The results showed that diabetes mellitus represented $34.2 \%$ of all sick leave requests associated with endocrine 